\title{
REPRESENTAÇÕES DO FEMININO: ANTÔNIO VIEIRA E A DOUTRINA DOS ARQUÉTIPOS - PANDORA, EVA E AVE MARIA
}

\author{
Felipe Lima da Silva ${ }^{1}$
}

\begin{abstract}
RESUMO: É evidente a retomada das referências à mulher em grande parte das manifestações artísticas ao longo da história da cultura e das religiões. A (sobre)vivência da figura do feminino, por sua vez, condicionou-se a formas diversas de representação - da matriz greco-romana à era do Catolicismo ortodoxo ou, em outros termos, da figura de Pandora à de Eva, plasmando, no intervalo dos tempos, como forma digna de imitação dos costumes, a imagem da Virgem Maria. Aqui, proponho pinçar um momento particularmente interessante na historiografia literária lusobrasileira, examinando um sermão de Antônio Vieira, orador sacro dos mais admirados no século XVII, dirigido inteiramente às mulheres, para ilustrar as encenações do feminino sob o prisma do Cristianismo. Especificamente, analisarei um sermão pregado, em 1651, para as religiosas do Patriarca São Bernardo, no Convento de Odivelas, em Portugal, cuja unidade de sentido, operada sob a lógica pragmática, é estabelecer uma crítica aos hábitos das freiras que passavam horas do dia em frente ao espelho, objeto este que, para o sermonista em foco, é uma metonímia do "demônio mudo", que seria muito mais astucioso que qualquer outro demônio, até mesmo do que a serpente que persuadiu Eva no Paraíso. Partindo desse pressuposto, podemos entrever deslocamentos e reciclagens da simbologia conceitual da hýbris como desmedida, uma vez que Vieira continuamente estabelece relações com o mundo do paganismo, demonstrando que as ações das esposas do Céu as freiras - são execráveis, pois são frutos de duas correntes censuráveis: por um lado, essas ações são herança de Eva pecadora e, ao mesmo tempo, são dignas de repúdio, pois vão ao encontro de uma prática antissocrática carregada de exageros e imoralizações. No fio condutor de nossa leitura, a býbris é simbolizada nas dobras da vanitas - vaidades e futilidades - refletidas no espelho, significando um desacordo entre a vida no claustro e os costumes padrões de uma freira, que ultrapassa os limites do comportamento quando se empenha na ornamentação do invólucro carnal, esquecendo-se de embelezar a face da alma.
\end{abstract}

Palavras-Chave: Arquétipos do Feminino; Padre Antônio Vieira; Literatura e Religião.

\section{REPRESENTATIONS OF THE FEMININE: ANTÔNIO VIEIRA AND THE ARCHETYPES DOCTRINE - PANDORA, EVE AND AVE MARIA}

\begin{abstract}
Over the history of culture and religions, it is evident that the reference to the women have been retaken in many artistic expressions. The livingness, or should we say, survival of the feminine has conditioned itself to many types of representation - from the Greco-Roman origin to the Orthodox Catholicism or, in other words, from Pandora to Eva, and, in between times shaping the image of Virgin Mary. In this communication, we will propose the choose of a moment particularly interesting in the Luso-Brazilian literary historiography, by examining a sermon from Antonio Vieira, one of the most admired orators in the seventeenth century, fully directed to the women, in order to illustrate the representations of the feminine under Christianity. More specifically, we will analyze a sermon preached in 1651 for the religious women of Patriarca São Bernardo, from the Convento das Odivelas, in Portugal; its unity of sense, operated by the pragmatic logic, stablishes a critics over the habits of the nuns, who used to spent many hours in front of the mirror, considered by the preacher as a metonym of the 'silent demon', more daring than any other demon, even the persuasive serpent in Heaven. From this supposition, we can glimpse dislocations and recycles from the conceptual symbolism of hybris as unmeasured, as Vieira continually stablishes relations with the pagan world, demonstrating that the actions of the nouns
\end{abstract}

${ }^{1}$ Graduado em Letras pela Universidade do Estado do Rio de Janeiro (UERJ); Mestre em Literatura Brasileira pelo Programa de Pós-Graduação em Letras da Universidade do Estado do Rio de Janeiro (UERJ). 
are horrible, because they origin from two censurable trends: on one hand, these actions are an inheritance from Eva and, at the same time, are reprehensible, because they respond to an antiSocratic practice, full of exaggerations and non-moralizations. In this lecture, bybris symbols itself under vanitas - the vanities and futilities - reflected in the mirror as a disagreement between life in the cloister and the costumes of a nun, who exceeds the limits of behavior when she endeavors embellishment of body and forgets to embellish the soul.

KEYWORDS: Feminine archetypes; Father António Vieira; Literature and Religion

Eva: "Um sabor que nunca homem algum experimentou. Agora aos meus olhos tornaram-se tão claros, que eu me sinto como Deus todo-poderoso. Tudo o que foi, tudo o que será, tudo o que sei e sou. Come, Adão, não hesites, pegá-la-ás em boa hora. [...]

Adão: "Crereis no que diそ, tu és meu par". (apud AUERBACH, 2013, p. 127).

O ponto inicial de nossa investigação consiste no olhar atento sobre as passagens acima, constituídas por algumas das falas - talvez as mais emblemáticas - as quais dão corpo a um diálogo entre Adão e Eva presente no manuscrito medieval, Mistery d'Adam, descrito como uma peça natalina de fins do século XII.

O texto é minuciosamente estudado pelo crítico Erich Auerbach, em seu clássico livro Mímesis (2013). O que chama atenção do crítico e filólogo é a novidade que traz o texto, quando comparado ao Gênesis, da Bíblia. Esquematicamente haveria na peça teatral uma série de elementos peculiares em contraponto ao texto sagrado: 1) a introdução de um diálogo entre Adão e Eva; 2) a alusão à tentativa anterior do diabo de seduzir primeiro Adão ao pecado. Desconsidero, dado o escopo deste trabalho, tratar detalhadamente deste diálogo aqui, mas noto ser relevante acentuar que o mundo cristão já desenhara, na representação deste acontecimento, a cena da extrapolação dos limites estipulados por Deus para os homens.

Por vezes, ao tocar no tema do pecado original, como assim o chamou pela primeira vez Santo Agostinho, podemos entrever similaridades entre tal acontecimento e a noção de býbris do mundo clássico. Retomando a noção de desmedida (býbris), para lidar com as narrativas dos maiores heróis da mitologia antiga, deixamos, possivelmente, de considerar que a própria noção de pecado original, que é plasmada e reformulada pelos primeiros Padres e Doutores da Igreja, da Antiguidade Tardia, tais como Santo Agostinho (séc. IV-V) e Santo Tomás de Aquino (séc. XIII), por exemplo, vai, de alguma forma, ser reconstruída a partir da mesma ideia de býbris enquanto cruzamento da linha do que é considerado o limite para o homem. Basta lembrar que Aristóteles já dizia que o herói é 
aquele que se destaca entre os demais, justamente, por ultrapassar os limites para alcançar a glória.

Em termos mais restritos, destaquemos que, aqui, o sentido de býbris empregado assume o desenho da definição apresentada por Carlos Ceia em seu Dicionário de termos literários (2010), no qual afirma que o conceito grego representa uma violência, pois, ao ultrapassar o métron, o homem estaria cometendo a insolência, um ultraje, na pretensão de competir com a divindade.

No âmbito ainda mais específico da mentalidade judaico-cristã, a desmedida alimentaria a engrenagem da rebeldia, que é condenável e merece ser expurgada, pois ninguém deve igualar-se a Deus. Nesse sentido, Erich Auerbach apreende, ao ler a peça aqui mencionada, o ato primevo de rebeldia no mundo cristão: "Eva tira a maçã da árvore e seduz Adão a comê-la” (2013, p. 128). Eis que, a partir desse juízo, todas as mulheres estariam condenadas a pagar pelo erro de Eva.

Não podemos deixar passar em silêncio o fato de que a cena primordial do Gênesis, aqui referida, fica muito próxima da cena significante da narrativa do famoso mito de Pandora, considerada a primeira mulher no paganismo. Uma coisa é certa: a curiosidade é a pedra angular que mobiliza e converte a ação dessas mulheres em rebeldia perante a divindade. Para Dora e Erwin Panofsky (2009, p. 23), em sua busca pela sobrevivência do mito de Pandora na história da iconografia, é possível afirmar que, na Idade Média, já haveria uma tentativa dos escritores eclesiásticos e seculares em corroborar a doutrina do pecado original, recorrendo a um paralelo clássico entre Eva e Pandora, ainda que isso significasse opor a verdade cristã a uma fábula pagã.

As semelhanças são notórias e não exigem que nos detenhamos particularmente sobre elas, mas é fulcral sublinhar os efeitos que atingiram as mulheres. Para assegurar a veracidade do discurso religioso judaico-cristão, muitas vezes recorreu-se aos mitos pagãos, reformulando-os de modo a incorporá-los e adaptá-los como exemplos para fortalecer as narrativas bíblicas toda vez que justificavam a inferioridade feminina. Dito isto, já podemos compreender que todo esse aparelho discursivo de repressão sobre a figura feminina será conduzido e hiperbolizado ao longo da história sacra, acentuando-se gradativamente no cenário da Reforma e da Contrarreforma.

Nestas linhas, portanto, vou me ater, estritamente, a um sermão proferido pelo eminente orador sacro português, Padre Antônio Vieira, pregado em 1651, para as 
religiosas do Patriarca São Bernardo, no Convento de Odivelas, em Portugal. Para os propósitos desta análise, entretanto, faz-se necessário tecer algumas considerações que reconstituam o panorama da condição da mulher a fim de melhor compreender o contexto do século XVII ibérico.

Conforme se sabe, a condenação da mulher data de longe, origina-se do episódio no Éden, mas, quando necessário, reforça-se no cerne dos mitos pagãos. No começo da Idade Moderna, o imaginário masculino sobre o feminino está impregnado de terror e desprezo. De acordo com o importante historiador francês Jean Delumeau (1989, p. 310), "a mulher foi então identificada como um perigoso agente de Satã; e não apenas por homens da Igreja, mas igualmente por juízes leigos”. A mulher é assimilada como uma eterna contradição viva.

Ainda sob as lentes do referido historiador, o homem, a fim de valorizar-se, definiu-se, por excelência, como apolíneo e racional, por oposição à mulher dionisíaca e instintiva, mais invadida que ele pela obscuridade, pelo inconsciente e pelo sonho. A ela restou o posto de encarnação da própria sedução - herança direta de Pandora -, mas que, ao mesmo tempo, repele o "primeiro sexo" pelo seu fluxo menstrual, pelos odores, pelas secreções corporais, pelo líquido amniótico, pelas expulsões do parto (DELUMEAU, 1989, p. 311).

A repulsão "ao segundo sexo" era fortalecida pelo espetáculo da decrepitude física de um ser mais próximo da matéria do que o homem e, portanto, mais rápida e mais visivelmente "perecível" do que aquele que pretende encarnar o espírito. Desse modo, explica-se o grande fascínio da mulher pelos ornamentos cosméticos que encobriam as chagas deixadas pelo abandono da beleza física. Lembre-se que a terra mãe é o ventre nutridor, mas também o reino dos mortos sob o solo ou na água profunda (cf. DELUMEAU, 1989, p. 312).

Considerada, desde a ótica aristotélica como um "macho deficiente", a mulher será incapaz de governar a si própria, necessitando de um homem "perfeito por sua razão e mais forte em virtude" (DELUMEAU, 1989, p. 317). É evidente que esse descrédito da figura do feminino será acentuado pelos eventos já mencionados aqui, porém, também é válido frisar que existirão momentos nos quais o universo feminino voltará a respirar através de imagens modelares traçadas como formas da boa conduta moral: o maior dos arquétipos, sem muito esforço do pensamento, é a Virgem Maria, mãe do filho de Deus. 
Assinalemos, ainda que brevemente, que a Idade Média consagrou a Maria uma extensa cadeia iconográfica das mais belas e imortais obras de arte, bem como inventou o amor cortês, que reabilitou a atração física, colocando a mulher sobre um pedestal a ponto de fazer dela a suserana do homem apaixonado e o modelo de todas as perfeições.

Em paralelo a isso, o historiador da arte Georges Didi-Huberman, em seu livro Ouvrir Venus (1999), corrobora essa ideia ao demonstrar que há uma série de produções iconográficas nas quais a sobrevivência do interesse pela anatomia feminina foi tema recorrente no Renascimento até as obras pictóricas do século XVIII, épocas em que os saberes relacionados à medicina estavam em plena expansão.

Antes de determo-nos, especificamente, no solo da pregação vieiriana, elucidemos, de passagem, lguns juízos sobre a imagem da mulher em meados do século XVI e início do XVII. Comecemos destacando as palavras do jurisconsulto Boutillier, frequentemente editado duzentos anos mais tarde, as quais referiam que

A mulher não pode, nem deve de modo algum ser juiz, pois ao juiz cabe enorme constância e discrição, e a mulher, por sua própria natureza, delas não está provida. Igualmente, são privadas as mulheres de serem advogados da corte em razão da sua impetuosidade. Em Namur, um decreto urbano de 1687 proíbe as professoras primárias de ensinar meninos: seria "indecente". Por fim, alguns tribunais admitiam que um testemunho de um homem valia por de duas mulheres (DELUMEAU, 1989, p. 336).

As razões anteriormente mencionadas nos levam a diagramar que a condição do feminino foi gerada por imagens emblemáticas que no início dos tempos agiram de modo inconsequente, alimentando uma deturpada mentalidade repressora, o que, paradoxalmente, promoveu a criação de imagens que realizassem uma ligação com a salvação, plasmadas no intervalo dos tempos e criadas para compor um ideal de moral que banisse as referências negativas que associavam a imagem da mulher às conotações mais perversas, tais como "flecha de Satã" e "sentinela do inferno" (cf. DELUMEAU, 1989, p. $337)$.

Não esqueçamos que a escolha do nome é significativa. A Ave pronunciada um dia pelo anjo Gabriel reverte a ação empenhada um dia por uma mulher de nome Eva (cf. DIDI-HUBERMAN, 2007, p. 216). Em síntese, nominal e moralmente falando, a teologia assenta um topos diametralmente oposto para a primeira mulher, que condenou sua espécie, ao criar um epicentro da salvação para a humanidade, posicionando nesse tabuleiro, por 
outro, Maria, não apenas como mulher paradigmática, única digna de imitação, mas como o eixo gerador da Salvação do homem: mãe do Verbo Encarnado ${ }^{2}$.

De igual maneira importa sublinhar que, dada a plasticidade da forma feminina em relação à silhueta masculina, a mulher foi preferencialmente utilizada como figura para personificar abstrações: a Castidade, a Verdade, a Caridade, a Natureza, a Majestade, a Religião, a Sabedoria, a Força e até mesmo os "Nove Cavaleiros", os “Quatro Elementos", as "Quatro Virtudes Cardeais" e as "Quatro partes do mundo". Essas alegorias em forma de emblemas, lembremo-nos da obra de Andrea Alciato (1531), estavam impregnadas de uma moralização que influenciava diretamente no caráter pedagógico da "literatura" da época.

Essa promoção é parcial, evidentemente, pois todas as alegorias, como Minerva (ou as Amazonas), assim como a Virgem Maria, são produzidas para diretamente funcionar como dispositivos anti-Eva. São mulheres que não realizam a totalidade da sua condição feminina, sendo colocadas acima ou fora da zona dos pecados sexuais.

Uma constatação: quando figuras femininas personificam abstrações, estão vestidas à antiga com togas flutuantes, por vezes colocadas em um pedestal e cercadas por uma paisagem idílica. Em contrapartida, quando encarnavam alegorias nefastas, usavam trajes da época e estavam inseridas no cenário cotidiano. Isso significa que "a mulher virtuosa é repelida para fora do real, enquanto a mulher má é nele introduzida de pleno direito" (DELUMEAU, 1989, p. 345).

Nesse passo do texto, já podemos nos introduzir no campo de força da oratória moralizadora de Antônio Vieira, contextualizados com as figurações femininas que permeiam o imaginário "misógino" da época. A crítica do pregador é incisiva sobre as freiras do convento de Odivelas, que, para ele, estavam mais preocupadas em ornar sua imagem física do que emular a imagem da Virgem Maria, passando, desse modo, a maior parte de seu tempo na frente do espelho que, para Vieira, é o pior de todos os demônios: "vem mudo, [e] debaixo do mesmo silêncio, em que se esconde o perigo, descansa, e adormece o cuidado" (2015, p. 144).

Esclareçamos. Considerada uma das esposas de Cristo, a freira devia seguir o modelo de Maria e repudiar qualquer parentesco com Eva, figura à qual estava ligada pela

\footnotetext{
2 Para maiores detalhes sobre a produção de imagens na sermonística do Padre Antônio Vieira que parte da iconicidade circular e relacionam-se ao Verbo Encarnado, instituindo uma mística plástica assentada na teologia neoescolástica, ver SILVA, 2015.
} 
sua condição de mulher. A vida nos conventos, além disso, era condicionada por questões sociais. Por esse motivo, a reclusão das mulheres era mais de ordem social do que sexual, de modo a evitar um casamento com pessoas inferiores a elas (cf. HANSEN, 2008, p. 553).

Com efeito, podemos inferir que o convento de Odivelas, como explica Ana Lúcia de Oliveira (2009, p. 2), sempre foi habitado por ilustres figuras, contudo gradualmente 'a santidade' do local foi sofrendo alterações, visto que a maioria das suas habitantes se encontrava ali enclausurada não por vocação, mas por imposições.

Seguindo o curso da argumentação de Vieira, é fundamental elucidar a técnica de todo orador que consiste em lançar mão do arsenal mítico para assegurar a força discursiva de seu sermão. Para repreender a vaidade das freiras, que mais dedicavam seu tempo ao espelho do que ao altar, ultrapassando os limites da conduta religiosa, o pregador passa a configurar o espelho como o mediador, se não, a própria metonímia dessa býbris que causa a perdição das seguidoras de Maria:

O espelho [...] foi invento artificial, e humano. Porém em sua primeira origem já tinha sido o espelho obra da natureza, e do Soberano Autor dela. As estrelas são espelhos do Sol; os rios são espelhos das árvores; uma fonte, que não devera, foi espelho fatal de Narciso. [...] Séneca com toda a severidade Estoica diz que os espelhos [...] foram ordenados desde seu princípio pela natureza, como mãe, e mestra dos bons costumes, para que o moço que nasceu bem afigurado, vendo no espelho a sua gentileza, a não afeasse com os vícios: e o que nasceu feio suprisse, e emendasse aquele defeito com a formosura das virtude (VIEIRA, 2015, p. 149).

Esse exercício retórico-hermenêutico do Padre Vieira sobre a filosofia de Sêneca é crucial para o que propomos aqui, posto que, como toda interpretação bíblica operada na época, tende a nos encaminhar aos fins pragmáticos já pré-estabelecidos no sermão. Ora, o jesuíta está pregando para um grupo de freiras de um famoso convento, e sua finalidade é fazer-se persuasivo a todo o momento. Nesse sentido, todo o aparelho da máquina retórica contrarreformista é utilizado para alcançar esse primado, inclusive a própria utilização da mitologia e da filosofia pagãs, que fazem parte do imaginário católico-ortodoxo, como bem se sabe.

É sob a legitimidade dessa interpretação autorizada pelo Concílio de Trento que os pregadores seiscentistas e, mais particularmente, Antônio Vieira, vão poder traçar leituras agudíssimas da tradição. Ainda na esteira da configuração negativa do espelho, afirma o pregador: 
Não há duas coisas que Deus criasse mais parecidas, e semelhantes, que o demônio e o espelho. O demônio primeiro foi Anjo, e depois demônio: o espelho primeiro foi instrumento do conhecimento próprio, e depois do amor-próprio, que é a raiz de todos os vícios (VIEIRA, 2015, p. 149).

Não se pode deixar de fazer menção ao tratado de Tertuliano, De Idolatria, no qual a prática de idolatria é entendida como a mais perversa entre todos os pecados, sendo considerada como crime capital. De acordo com Vieira, o amor-próprio não apenas está na raiz de tudo, como é a própria raiz de tudo, pois é ele que nos exorta a querer mais, assim como saber mais. Em concordância com o já dito até aqui, a curiosidade e a exaltação próprias já causaram os graves problemas na história.

Procurando corroborar o seu argumento, o orador inaciano se dispõe a estabelecer um sutil paralelo entre as ações de Lúcifer e Narciso - este o mais belo entre todos; aquele o maior Anjo entre todos. Assim conclui:

Isto posto, tanto que foi criado o maior, e mais excelente de todos os Espíritos Angélicos, Lúcifer, viu-se neste seu espelho mental, e contemplando nele a sua formosura, maior sem controvérsia que a de todos os Anjos, ficou tão namorado e elevado da mesma vista: Elevatum est cor tuum in decore tuo, que não se contentou com menos que ser como Deus (VIEIRA, 2015, p. 150).

Debaixo do intuito de demonstrar a grandeza do erro das irmãs de Odivelas, Antônio Vieira personifica a figura do espelho, colocando-a plano de comparação com as figuras de Deus e do demônio. Reforçando a perversidade do objeto, o pregador demonstra que na medida em que a freira cede aos caprichos da vanitas, consequentemente, entrega-se ainda mais ao próprio demônio.

O demônio permite à freira ver aquilo que o arbítrio deseja, mas que, quando insatisfeita, recorre às drogas cosméticas as quais, na longa tradição da filosofia e da história da arte, já teriam recebido as conotações mais funestas. Leiamos:

Só não se pode fazer o demônio que as que se veem ao espelho, como querem, sejam vistas também como querem; mas isto supre as receitas, que se vão buscar à botica, que no mesmo espelho ensina por acenos o mesmo diabo mudo (VIEIRA, 2015, p. 153).

Acentuando sua crítica, o nosso Padre toca no ponto que talvez aqui mais nos interesse. Recorre à árvore genealógica para ampliar a zona de alcance de sua repressão sobre as mulheres:

É possível que uma virgem consagrada a Deus, e desposada com o Filho de Deus, há de estar tão casada com o espelho? É ela mulher? É ela filha 
de Eva? Pois de lá the vem esta inclinação; e não é muito que tenha lançado tão fortes raízes. [...] Se já houvesse [no Paraíso] também os espelhos, aos quais fosse lícito enganar, e mentir, como hoje fazem, que também Eva se havia de deixar enganar deles (VIEIRA, 2015, p. 153).

Ainda que essa experiência do demônio transvertido em espelho não tenha sido vivenciada pela primeira mulher da cosmologia judaico-cristã, afirma o pregador assim mesmo que "bem se viu, depois que os houve, o apetite que herdaram da mesma Eva as suas filhas” (VIEIRA, 2015, p. 157). Esse “apetite mulheril”, referência à vaidade feminina, é uma herança direta de Eva que ficou legada às filhas.

O espelho é digno de condenação eclesiástica, pois ele é um instrumento de emulação que, na lógica platônica, duplicaria, ainda que (im)perfeitamente, cópias de graus inferiores. Ele não tem a potência criadora da ideia imanente e inatingível. Sinopticamente, o espelho é instrumento de deturpação da imagem, pois desfigura a alma dentro da lógica dos dogmas católicos. O espelho é a metonímia da própria býbris, pois é o instrumento que faz a freira, especificamente, desviar-se de seu caminho rumo às colinas celestes.

Para que estas linhas não se estendam demasiadamente, convém tecer algumas considerações finais sem que instituamos conclusões cerradas. Nada mais categórico, podemos dizer, do que encerrar o texto por meio do próprio desfecho do sermão, em que o pregador propõe uma resolução lapidar para que as freiras possam se redimir perante os céus. Propõe a essas mulheres abdicarem do espelho em favor de colocar em seu lugar "duas Imagens que suponho haver em todas as celas; uma do mesmo Senhor, que hoje lançou fora o demônio mudo, e outra da Virgem Santíssima". Logo explica que: "Nestas duas Imagens, as mais santas, e soberanas de todas, se fará uma segunda, espelhos, em que se estão continuamente vendo, e revendo os Bem-aventurados do Céu” (2015, p. 168).

No remate da pregação, pontuemos a mais célebre menção que faz o Padre Vieira ao universo pagão a fim de imprimir uma imagem eterna para os olhos das freiras sobre o ideal de beleza feminina entendido sempre como "perecível". Em razão disso, utiliza-se da técnica retórica da teatralização, personificando o espelho de modo que pareça ser o próprio objeto que está falando com as freiras.

Poupemos conclusões, deixemo-nos embeber pelo remate figural do pregador que joga com as fronteiras culturais para tecer redes alegóricas plasmadas pelas maravilhas engenhosas, que imperam e operam em seu sermão como forças de doutrinação, postas à máquina do mundo, neste caso, impostas ao universo feminino: 
A formosura (diz ele) é um bem frágil, e quanto mais se vai chegando os anos, tanto mais vai diminuindo, e desfazendo em si, e fazendo-se menor. Seja exemplo desta lastimosa fragilidade Helena, aquela famosa, e formosa Grega, filha de Tíndaro, rei de Lacônia, por cujo roubo foi destruída Troia. Durou a guerra dez anos, e ao passo que ia durando, e crescendo a guerra, se ia juntamente com os anos diminuindo a causa dela. Era a causa, a formosura de Helena, flor enfim da terra, e a cada ano cortada com o arado do tempo [...] que vendo-se ao espelho, pelos olhos, que já não tinham a antiga viveza, lhe corriam as lágrimas, e não achando a causa, por que duas vezes fora roubada. (VIEIRA, 2015, p. 170).

\section{REFERÊNCIAS:}

ALCIATO, Andrea. Emblemas. Edición de Santiago Sebastián. Madrid: Akal, 1993.

AUERBACH, Erich. Adão e Eva. In: Mimesis: a representação da realidade na literatura ocidental.

São Paulo: Perspectiva, 2013.

DELUMEAU, Jean. História do medo no Ocidente (1300-1800). Tradução de Maria Lúcia Machado. São Paulo: Companhia das Letras, 1989.

DIDI-HUBERMAN, Georges. Ouvris Vénus: nudité, revê, cruauté. Paris: Gallimard, 1999.

DIDI-HUBERMAN, Georges. L' image ouvert: motifs de l'incarnation dans les arts visuels. Paris:

Gallimard, 2007

HANSEN, João Adolfo. "Pedra e cal: o amor freirático na sátira luso-brasileira do século XVII”. In: Destiempos. México, Distrito Federal, marzo-abril 2008, Año 3, número 14, p. 554-565.

OLIVEIRA, Ana Lúcia de. "Entre o demônio mudo e as mulheres: Antônio Vieira e a crítica à vaidade feminina". In: Atas do XII Seminário Nacional e VI Seminário Internacional Mulher e literatura, UFRN, setembro, 2009.

PANOFSKY, Dora e Erwin. A caixa de pandora: as transformações de um símbolo mítico. Tradução de Vera Pereira. São Paulo: Companhia das Letras, 2009.

SILVA, Felipe Lima da. Imagem encarnada: encenações da mística plástica na sermonística de Antônio Vieira. In: Linguagem em (Re)vista. Vol. 10, n. 19. Niterói, jan.-jun./2015, p. 6784. Disponível em: http://www.filologia.org.br/linguagememrevista/19/04.pdf

VIEIRA, Antônio. "Sermão do Demônio mudo". In: Obra completa Padre Antônio Vieira: Sermões da Quaresma. vol. 3, Tomo II, São Paulo: Edições Loyola, 2015.

Data de recebimento: $11 / 04 / 2017$

Data de aprovação: 23/12/2017 